\title{
Chitosan and gum arabic nanoparticles for heavy metal adsorption
}

\author{
Flavia Oliveira Monteiro da Silva Abreu ${ }^{1 *}$, Nilvan Alves da Silva1, Mateus de Sousa Sipauba', \\ Tamara Fernandes Marques Pires², Tatiana Araújo Bomfim², Oyrton Azevedo de Castro Monteiro Junior ${ }^{2}$ \\ and Maria Madalena de Camargo Forte ${ }^{3}$
}

\author{
'Laboratório de Química Analítica e Ambiental - LAQAM, Centro de Ciências Tecnólogicas - CCT, \\ Universidade Estadual do Ceará - UECE, Fortaleza, CE, Brasil \\ 'Laboratório de Química Tecnológica, Centro de Ciências Tecnológicas - CCT, Universidade de Fortaleza \\ - UNIFOR, Fortaleza, CE, Brasil \\ ${ }^{3}$ Laboratório de Materiais Poliméricos - LaPol, Departamento de Engenharia dos Materiais - DeMat, \\ Escola de Engenharia - EE, Universidade Federal do Rio Grande do SuI - UFRGS, Porto Alegre, RS, Brasil \\ *flavia.monteiro@uece.br
}

\begin{abstract}
Chitosan (CT) is a polysaccharide with the ability to adsorb metals on its surface. In this work, CT-based nanoparticles (NPs) are produced by complex formation with gum arabic (GA) to increase their adsorbent potential for removal of heavy metals in aqueous medium. Adsorption efficiency is evaluated as a function of NP composition and polysaccharide concentration. NPs are sized from 250 to $375 \mathrm{~nm}$ at a zeta potential up to $-25 \mathrm{mV}$, suggesting stability to adsorb metals. In particular, CTGA56 and CTGA80 NPs adsorbed a substantially higher amount of copper ions than pure CT. Adsorption kinetics studies showed that the reaction process followed a pseudo second-order model and the adsorption isotherm results fit a Langmuir model, highlighting the monolayer adsorption process with prominent adsorption capacity. These findings indicate the adsorbent potential of CTGA NPs and suggest that these particles can be used for removal of metal ions from contaminated water sources.
\end{abstract}

Keywords: adsorption, chitosan, nanoparticles, polyelectrolytes.

\section{Introduction}

Water is a natural resource that is essential for life. As such, problems related to water quality, such as contamination by highly toxic and non-biodegradable heavy metals that are a by-product of industrial, domestic, or agricultural activities, are of significant concern ${ }^{[1,2]}$. Recent ecological studies have reported high levels of metal in urban environments such as rivers that exceed the safe limit for drinking water and create harmful conditions for surrounding biota and inhabitants ${ }^{[3]}$.

There are several methods for removing heavy metals from wastewater, including chemical precipitation, filtration with activated carbon, reverse osmosis, and coagulation ${ }^{[4]}$. Biopolymers such as chitosan (CT) have been tested for their potential for metal adsorption, especially given their low cost and abundance in nature. Biosorption is a physico-chemical and metabolically independent process for the removal or recovery of organic and inorganic substances from solution using biological materials that involves a variety of mechanisms including absorption, ion exchange, surface complexation, and precipitation ${ }^{[5]}$. CT is derived from deacetylated chitin from the exoskeleton of crustaceans and exhibits hydrophilic characteristics, biocompatibility, and biodegradability. The adsorption capacity is attributed to the presence of a large number of amino and hydroxyl groups in the polymer chain that act as active sites of metal coordination $^{[6-9]}$.
Amino groups of CT composites and derivatives presents well stabillished binding properties with some heavy metal ions such as $\mathrm{Cu}(\mathrm{II}), \mathrm{Zn}$ (II), $\mathrm{Ni}(\mathrm{II}), \mathrm{Cd}(\mathrm{II}), \mathrm{Pb}(\mathrm{II}), \mathrm{Hg}(\mathrm{II})$, and $\mathrm{Cr}(\mathrm{VI})^{[10]}$; cations and anions of dyes; and protein molecules in aqueous medium via various types of interactions including electrostatic attraction, coordinated bonds and chelation ${ }^{[11]}$. Various studies have evaluated the absorbing capacity of CT combined with other materials, such as with cellulose, alginate, and silica ${ }^{[9,12]}$. Gum arabic (GA) is a natural anionic polysaccharide derived from tree exudates of Acacia senegal and Acacia seyal whose chemical composition can vary with the age of the tree, climate, and regional soil conditions ${ }^{[13]}$. Although GA has been used for protein encapsulation and delivery ${ }^{[14]}$, its potential for metal absorption has not yet been reported. Nevertheless, GA presents carboxyl groups which may act as a binding agent to enhance the adsorption potential of chitosan.

In the present study, CT and GA nanoparticles (NPs) were synthesized by polyelectrolytic complexation based on electrostatic interactions arising from the opposite charges of the $\mathrm{CT}$ amino group (cation) and the anionic carboxylic group of GA in aqueous solution. The stability of such complexes depends on the composition and structure of the polymers as well as environmental factors such as temperature, $\mathrm{pH}$, and solvent characteristics ${ }^{[15,16]}$. Here, we examined the 
potential of the NPs for adsorption of heavy metal $(\mathrm{Cu})$ to evaluate their applicability to the treatment of contaminated bodies of water. The complexed polysaccharides in the form of NPs could present greater adsorption capacity than CT alone owing to a larger surface area and lack of internal diffusion resistance, where GA may offer additional binding sites thourgh their carboxylic groups ${ }^{[17,18]}$.

\section{Materials and Methods}

\subsection{Materials}

Gum arabic (GA) (Sigma-Aldrich Brasil, Ltda, São Paulo, SP, BR) with an average molecular weight of $400 \mathrm{kDa}$, low viscosity, and high solubility in aqueous medium and Chitosan (CT) Polymar, Fortaleza, CE, BR. with an average molar mass of $200 \mathrm{kDa}$ and deacetylation degree (DD) of $72 \%$ were used for experiments. The DD was determined by dissolving the CT sample in $20 \mathrm{ml} \mathrm{HCl} 0.100 \mathrm{M}$ followed by titration with $\mathrm{NaOH} 0.05 \mathrm{M}$.

\subsection{Preparation of CTGA NPS}

To obtain $2 \% \mathrm{w} / \mathrm{w}$ GA solution, $2 \mathrm{~g}$ of GA was added to $100 \mathrm{~mL}$ of distilled water with magnetic stirring for $2 \mathrm{~h}$. The stock solution was used to prepare $0.1 \%-0.3 \%$ solutions in a volumetric flask. A $2 \% \mathrm{w} / \mathrm{w}$ CT solution was prepared by adding $2 \mathrm{~g}$ of CT to $10 \mathrm{~mL}$ of $2 \%$ acetic acid (v/v) with stirring at a temperature of $60^{\circ} \mathrm{C}$ for $2 \mathrm{~h}$, and was diluted to obtain a $0.2 \% \mathrm{CT}$ solution. NPs were prepared by the complex coacervation method using $\mathrm{CT}$ as the nucleus. The $0.2 \% \mathrm{w} / \mathrm{v}$ CT solution was added dropwise to $30 \mathrm{mM}$ sodium pyrophosphate $\left(\mathrm{Na}_{4} \mathrm{P}_{2} \mathrm{O}_{7} \cdot 10 \mathrm{H}_{2} \mathrm{O}\right)$ using a $26-\mathrm{G}$ needle, followed by gelification under magnetic stirring for $30 \mathrm{~min}$. A molar ratio of 1:2 CT: $\mathrm{P}_{2} \mathrm{O}_{7}^{-4}$ was used for formation of the complexes. After gelification process, the pre-nucleus were coated with GA by controlled addition of a specific amount of GA solution, using $0.1 \%$ or $0.3 \%$, forming NPs with diferent final volume. The samples were homogenized for $1 \mathrm{~h}$ in order to form GA-CT NPs. The NPs were rinsed three times with distilled water by centrifugation at $3500 \mathrm{rpm}$ for $20 \mathrm{~min}$ and stored in distilled water under refrigeration for $12 \mathrm{~h}$. Afterwords they were spray-dried with inlet and outlet temperatures of $140^{\circ} \mathrm{C}$ and $60^{\circ} \mathrm{C}$, respectively, at a rate of $0.62 \mathrm{~L} / \mathrm{h}$ and air volume of $40 \mathrm{~L} / \mathrm{min}$.

\subsection{NPs Characterization}

NPs yield was determined from the ratio of the dry NP mass obtained by spray-drying to the total mass added to the reaction system. Average particle size and zeta potential were determined using a Zetasizer NanoZen3500 instrument (Malvern Instruments, Westborough, MA, USA). NPs were characterized by Fourier transform infrared (FTIR) spectroscopy in a Spectrum 1000 instrument using $\mathrm{KBr}$ disks (Perkin Elmer, Waltham, MA, USA).

\subsection{Adsorption studies}

The amount of adsorbed metal after $24 \mathrm{~h}$ was determined by the batch method in order to find the NPs with the best sorption capacity. The samples were compared with $\mathrm{CT}$ and GA, which were used as received from the manufacter. It was weighted $1 \mathrm{~g}$ of the samples CT, GA and the NPs, each one of them were immersed individually in a $1 \mathrm{M} \mathrm{CuSO}_{4}$ solution and the remaining amount of copper after $24 \mathrm{~h}$ was determined by complexometric titration using EDTA. A $2 \mathrm{~mL}$ aliquot was added to $50 \mathrm{~mL}$ of distilled water in a flask; the $\mathrm{pH}$ was adjusted to 10 , and the indicator Murexide P.A 99\% (Diadema, SP, BR) was added to the solution. The number of moles of adsorbed copper $\left(\mathrm{N}_{\mathrm{ad}}\right)$ was calculated using Equation 1:

$$
N_{a d}=\left(N_{f}-N_{i}\right) / m
$$

Where $\mathrm{Ni}$ and $\mathrm{Nf}$ are the initial and final number of moles, respectively, and $\mathrm{m}$ is the mass of the NPs immersed in $\mathrm{CuSO}_{4}$ solution of known concentration.

Kinetics of adsorption were evaluated by placing $50 \mathrm{mg}$ of NPs into $100 \mathrm{~mL}$ of copper sulfate solution at initial concentrations of 250, 1250, and $2500 \mathrm{mg} / \mathrm{L}$ at constant $\mathrm{pH}$ 6. $\mathrm{Cu}$ (II) adsorbed by NPs was measured after continuous stirring with a magnetic stirrer, where aliquots were taken at specified time points between 5 and $180 \mathrm{~min}$ and the $\mathrm{Cu}$ content was determined using an atomic spectrophotometer (Shimadzu, model AA-7000).

The amount of adsorption at equilibrium qe $(\mathrm{mg} / \mathrm{g})$ and at a given time qt $(\mathrm{mg} / \mathrm{g})$ were calculated by the following Equation 2 and 3:

$$
\begin{aligned}
& q_{e}=\left(C_{0}-C_{e}\right) \cdot V / m \\
& q_{t}=\left(C_{0}-C_{t}\right) \cdot V / m
\end{aligned}
$$

where $\mathrm{C}_{0}$ is the initial $\mathrm{Cu}$ (II) concentration, $\mathrm{C}_{t}$ is the concentration at a given time $\mathrm{t}$, and $\mathrm{Ce}$ is the concentration at equilibrium in $\mathrm{mg} / \mathrm{L}$, and $\mathrm{V}$ is the volume of the solution and $\mathrm{m}$ is the mass of the adsorbent.

\section{Results and Discussions}

CTGA NPs were produced using a primary complex of sodium pyrophosphate $\mathrm{Na}_{4} \mathrm{P}_{2} \mathrm{O}_{7}$ as a NP core to which GA was added at pH 6. Various CTGA NPs samples were produced by varying the $\mathrm{CT} / \mathrm{GA}$ ratio and the $\% \mathrm{GA}$ solution. NP properties were dictated by the intrinsic characteristics of the constituent polymer and the extent of interaction between polymers in solution. CTGA NPs were characterized by analyzing the zeta potential, yield, particle size and metal adsorption capacity.

NP yield was calculated based on the total mass added to the reaction. The overall yield was low because of loss of material during the spray-drying process, in comparison with freeze-drying process which tends to present higher yield ${ }^{[19]}$. Nonetheless, NPs with CTGA56 and CTGA48 (e.g., 56\% wt and 48\% wt CT content) had a higher yield than those in which there was an excess of one of the polysaccharides (e.g., $80 \%$ wt and $25 \%$ wt CT content), as shown in Table 1 . The CT had a lower molecular weight than GA, although they were both in the same order of magnitude (200 and $400 \mathrm{kDa}$, respectively). Thus, to obtain a higher yield of CTGA complexes, an 
Table 1. Nanoparticle Composition, Yield and Zeta Potential.

\begin{tabular}{lllcccc}
\hline NP Code & \multirow{2}{*}{ CT/GA mass ratio } & \multirow{2}{*}{ CT content (\%wt) } & $\begin{array}{c}\text { GA } \\
\text { solution (\%wt) }\end{array}$ & $\begin{array}{c}\text { Yield } \\
\mathbf{( \% )}\end{array}$ & $\begin{array}{c}\text { Zeta Potential } \\
\text { (mV) }\end{array}$ & Particle size (nm) \\
\hline CTGA80 & $4 / 1$ & 80 & 0.1 & 13.9 & -30.8 & 650 \\
CTGA56 & $1.3 / 1$ & 56 & 0.3 & 25.8 & -24.9 & 221 \\
CTGA48 & $1 / 1.1$ & 48 & 0.1 & 24.8 & -23.7 & 340 \\
CTGA25 & $1 / 3$ & 25 & 0.3 & 13.5 & -31.6 & $28(70 \%) 350(30 \%)$ \\
\hline
\end{tabular}

equivalent amount of GA with acidic groups is needed for electrostatic interactions with the amino groups of CT, which would favor electrostatic interactions. As discussed in the literature, during complexation, polyelectrolytes are formed when both polymers are ionised and bear opposite charges. Depending upon the strength of the interactions, the polyeletroctrolytes can either coacervate, or form a more or less compact hydrogel and if ionic interactions are too strong, precipitation can occur ${ }^{[15]}$. In this case $\%$ GA solution didn't affected the Yield in a direct manner, where neither NPs produced showed PEC precipitation.

In a previous related work regarding Chitosan-Alginate microparticles ${ }^{[19]}$, chitosan with lower MW, resulted in a higher yield in comparison with a chitosan with higher MW. Smaller chains presented less available amino groups per molecular chain and were used ina greater quantity to bind to the acid groups present in the ALG chains.

\subsection{FTIR spectroscopy}

CT, GA and CT/GA NPs were analyzed by FTIR spectroscopy. Vibration modes of the main groups of polysaccharides and their profiles are shown in Figure 1.

CT pure presents glucosamine units with stretching vibrations at $1420 \mathrm{~cm}^{-1}$ and $3379 \mathrm{~cm}^{-1}$. Their principal vibration modes are asymmetrical and symmetrical bending of amine and amide II bending at 1651 and $1556 \mathrm{~cm}^{-1}$, respectively. Also their acetyl-glucosamine groups appears at $1351 \mathrm{~cm}^{-1}$. For the GA, characteristic absorption bands were present, with a broad asymmetrical band at $1600 \mathrm{~cm}-1$ and a narrower symmetrical band at $1415 \mathrm{~cm}-1$, which can be attributed to $\mathrm{C}-\mathrm{O}-\mathrm{O}$ bond stretching and carboxylic ion axial stretching, respectively. An even broader absorption was observed near $1030 \mathrm{~cm}-1$, which can be attributed to $\mathrm{COH}$ stretching. Similar absorption bands are found in polyssacarides such as alginate ${ }^{[14,18,19]}$, and cashew gum ${ }^{[20,21]}$ in the literature.

As expected, all NPs showed similar profiles. A hydrocarbon group was detected in the CTGA NPs near $2900 \mathrm{~cm}^{-1[20]}$. Stretching vibrations from charged amino $\left(\mathrm{NH}_{3}^{+}\right)$groups were observed near $3380 \mathrm{~cm}^{-1}$. The main stretching of $\mathrm{GA}$ acid $\left(\mathrm{COO}^{-}\right)$groups overlapped with the asymmetric bending of $\mathrm{NH}_{3}^{+}$around 1600 and $1400 \mathrm{~cm}^{-1}$. It was notice that none of the CTGA NPs showed the usual CT amino band at $1566 \mathrm{~cm}^{-1}$. In another study, the disappearance of this particular amino band were a evidence of the complex formation of chitosan with a anionic polyssacaride ${ }^{[19]}$. With increasing GA content, a broadening of the band at $1400 \mathrm{~cm}^{-1}$ was observed, revealing a second smaller peak at $1344 \mathrm{~cm}^{-1}$. The absorption band at $1129 \mathrm{~cm}^{-1}$ was attributed

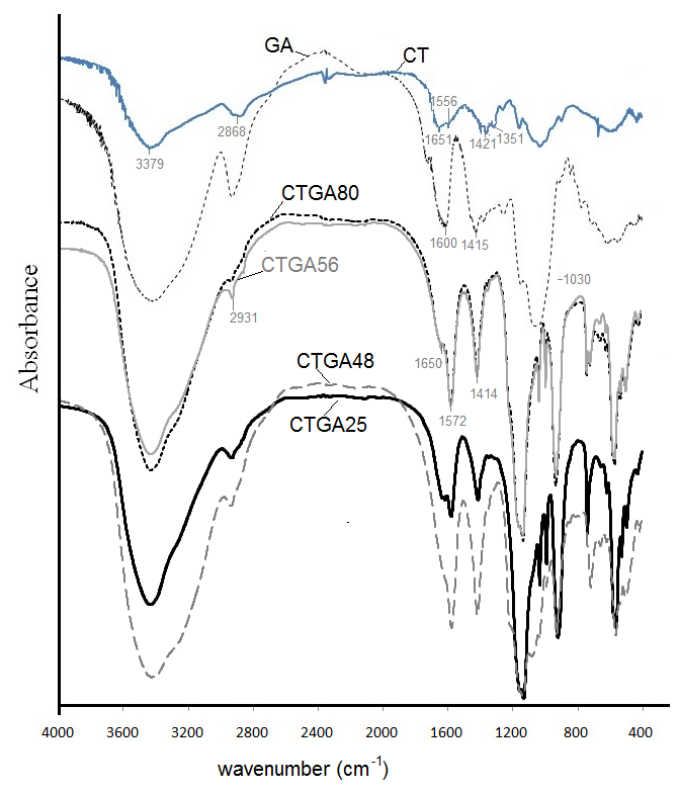

Figure 1. FTIR spectra of CT, GA and CTGA NPs.

to the stretching of $\mathrm{COH}$, whereas the amino group of CT in the $1414 \mathrm{~cm}^{-1}$ band presented an intensified peak ${ }^{[21]}$.

\subsection{Particle size and zeta potential}

Particle size and zeta potential were evaluated as a function of the total volume fraction of NPs. Particles with zeta potential values $>30$ or $\leq 30 \mathrm{mV}$ avoid undesirable fluctuations. In this study, all NPs had large negative zeta potential values that were $\leq 24 \mathrm{mV}$ at $\mathrm{pH} 6$ (Table 1). This result indicates that the CTGA NPs presents enough stability, where GA, an anionic polysaccharide, successfully coated the surface of the particle, formed by the CT in the inner core. Particle distribution pattern and average size are important factors that influence the ability of NPs to adsorb heavy metals, as showed in Figure 2. The CT/GA mass ratio were altered in order to investigate the effect of the excess of one of the components in the final average particle size. Also, the GA concentration was tested in two levels in order to investigate the effect on the NPs formation process. Theoretically, higher concentration of one component in a lower total volume could favor an excess of interactions and form inter-agregation complexes to the particles under formation and cause higher particle size $\mathrm{e}^{[19,22,23]}$.

Results showed a largely unimodal distribution pattern for NPs, indicating uniformity in the production process. 


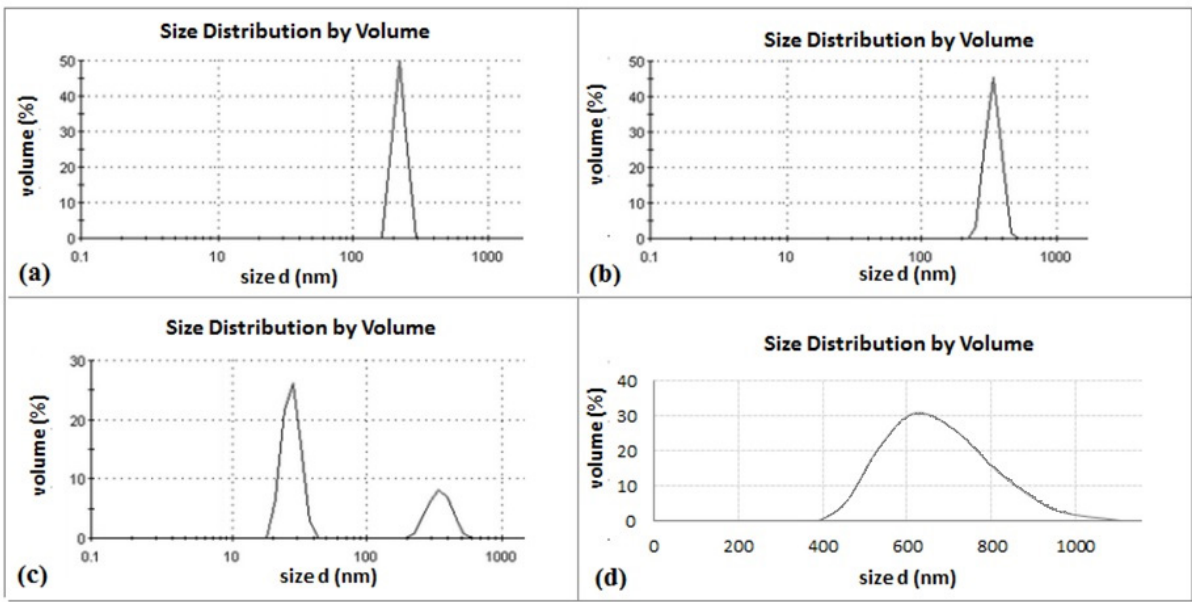

Figure 2. NP size distribution as a function of total particle volume. (a) CTGA56; (b) CTGA43; (c) CTGA33; (d) CTGA80.

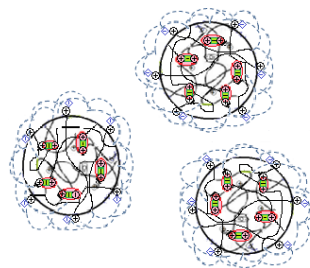

stable nanoparticles

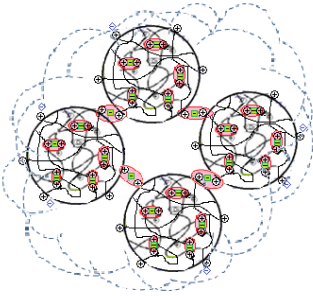

Aggregation of $\mathrm{CT}: \mathrm{P}_{2} \mathrm{O}_{7}^{-4}$ inner core $\Rightarrow$ higher particles

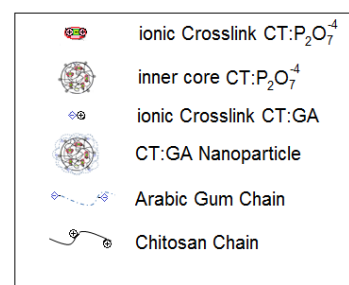

inner core $\mathrm{CT}: \mathrm{P}_{2} \mathrm{O}_{7}^{-4}$

ionic Crosslink CT:GA

T:GA Nanoparticle

Chitosan Chain

Figure 3. Formation of CTGA NPs without aggregation (left) and with possible aggregation of $\mathrm{CT}: \mathrm{P}_{2} \mathrm{O}_{7}^{-4}$ inner core (right).

NPs generally presented an average size of 250 - $350 \mathrm{~nm}$, and this size range comprised $>95 \%$ of the fraction volume. This size range would tend to enhance adsorption because of the higher surface area:volume ratio. However, NPs produced with a higher CT content presented a higher size ( $\sim 650 \mathrm{~nm}$ ), suggesting that the excess CT and their amino groups may have favored intra- and interionic interactions. These interactions would lead to aggregation of a CT: $\mathrm{P}_{2} \mathrm{O}_{7}^{-4}$ inner core, followed by a GA coating that would result in the formation of larger particles. This type of aggregation has been reported with other polysaccharides ${ }^{[19,22,23]}$ and is represented schematically in Figure 3.

\subsection{Adsorption properties}

Pure CT and GA as well the CTGANPs were evaluated for their ability to adsorb copper ions (Figure 4). The adsorption properties of pure CT were superior to those of pure GA ( $300 \mathrm{vs} .122 \mathrm{mg}$ of copper ions per gram of polymer). It is well known that chitosan is a powerful chelating agent that easily forms complexes with transition metals and heavy metals. Amino and hydroxyl groups are mainly involved in the binding of metal ions by chitosan ${ }^{[7-9]}$. Hence, the complex-forming properties and durability of a metal-chitosan complex depend on several parameters, such as the degree of

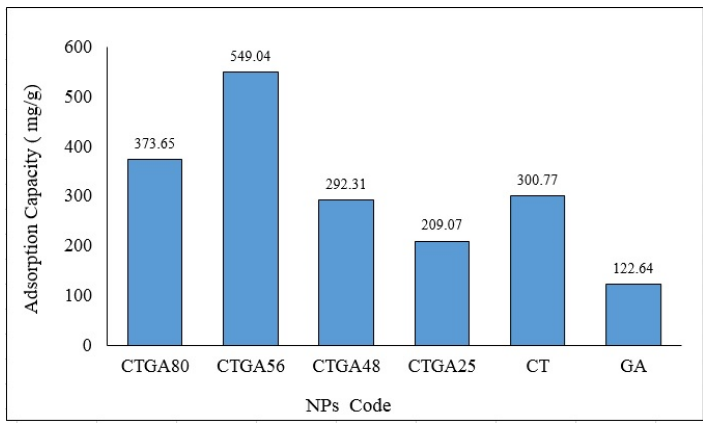

Figure 4. Adsorption of copper ions by CTGA NPs, CT, and GA.

deacetylation, the length of the polymer chain, and finally, the physical form of the adsorbent ${ }^{[24,25]}$. Accordingly, NPs produced with a higher $\mathrm{CT}$ content had a greater capacity for adsorption than those with a higher GA content, which was independent of average particle size. CTGA80 NPs presented the highest $\mathrm{CT}$ content, which presented the greatest amount of amino groups available for binding with copper ions. However, they presented lower adsorption 
properties at these conditions because of their higher particle size (>600 nm). CTGA56 NPs (with 56\% wt CT) had markedly higher copper adsorption $(549 \mathrm{mg} / \mathrm{g})$ than pure CT $(300 \mathrm{mg} / \mathrm{g})$. In this case, the combination of the high CT content and the nanoscaled particle size $(250 \mathrm{~nm})$ enhanced the adsorption capacity. The NPs in this study showed superior results compared to those in other studies of CTbased systems, such as CT-bound $\mathrm{Fe}_{3} \mathrm{O}_{4} \mathrm{NPs}(21.5 \mathrm{mg} / \mathrm{g})^{[24]}$, chitosan-coated perlite beads $(104.0 \mathrm{mg} / \mathrm{g})^{[25]}$, or chitosan/ cellulose $(26.5 \mathrm{mg} / \mathrm{g})$ and chitosan/alginate $(67.7 \mathrm{mg} / \mathrm{g})^{[9]}$. $\mathrm{CT}$ is already being used as alternative to activated carbon for the treatment of contaminated water bodies ${ }^{[1,6]}$. However, it is worth noting that our NPs had a different pattern from previously reported CT-core $\mathrm{NPs}^{[18]}$. The presence of GA in the NP coating may provide advantages in terms of stability because it does not swell under acidic conditions, as in the case of CT. Kinetics studies were conducted for CTGA56 and CTGA80 NPs because of their improved adsorption properties.

The effect of contact time on the adsorption capacities (mg/g) for NPs CTGA56 and CTGA80 as a function of the initial concentration of $\mathrm{Cu}$ (II) is shown in Figure 5. From these data, the equilibrium time for the adsorption was established as equal to $60 \mathrm{~min}$ for NPs CTGA56 and CTGA80, independently of the initial concentration. It was also noted that the adsorption rate of the metal complexes was higher at the beginning and thereafter achieved saturation level at $180 \mathrm{~min}$. This also shows that the adsorption capacities increased according to the increase of [Cu(II) $]$ concentration: 89, 961 and $2217 \mathrm{mg} / \mathrm{g}$

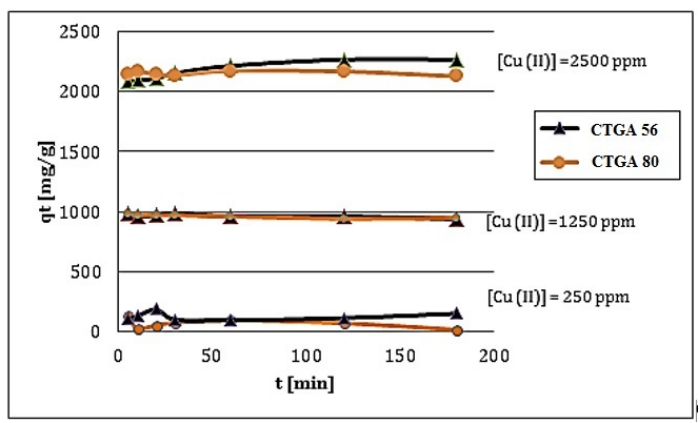

Figure 5. Effect of the phase contact time on the adsortion capacity of CTGA56 and CTGA80, depending on the concentration of $\mathrm{Cu}$ (II). for CTGA56 and to 109,940 and $2170 \mathrm{mg} / \mathrm{g}$ for CTGA80 for $\mathrm{Cu}$ (II) concentrations of 250, 1250 and $2500 \mathrm{mg} / \mathrm{L}$. This profile agrees with those reported in the literature ${ }^{[26-29]}$. Other studies showed different adsorption capacity; magnetic chitosan microspheres modified with thiourea adsorbed $80 \mathrm{mg} / \mathrm{g}$ with a copper ions concentration of $350 \mathrm{mg} / \mathrm{L}^{[28]}$; granular semi-IPN hydrogels based on chitosan and gelatin presented an adsorption capacity of $300 \mathrm{mg} / \mathrm{g}$ with a copper ions concentration of $1750 \mathrm{mg} / \mathrm{L}^{[29]}$. These results show that the prepared adsorbent has a very high $\mathrm{Cu}(\mathrm{II})$ adsorption capacity compared to reported in literature, particularly for higher concentration of $\mathrm{Cu}(\mathrm{II})$ in aqueous media.

\subsection{Kinetics of adsorption}

To investigate the mechanisms controlling adsorption processes such as mass transfer and chemical reaction, reaction and diffusion models were used to describe sorption kinetics. The kinetics of the processes were described by pseudo-first and pseudo-second order equations, represented respectively by Equation 4 and Equation 5:

$$
\begin{aligned}
& \log \left(q_{e}-q_{t}\right)=\log q_{e}-\left(k_{1} / 2,303\right) t \\
& 1 / q_{t}=\left(1 / k_{2} q e^{2}\right)+\left(1 / q_{e}\right) t
\end{aligned}
$$

where $\mathrm{q}_{\mathrm{e}}$ and $\mathrm{q}_{\mathrm{t}}$ are the sorption capacities for $\mathrm{Cu}(\mathrm{II})$ on CTGA NPs at equilibrium $(\mathrm{mg} / \mathrm{g})$ and at time $\mathrm{t}(\mathrm{mg} / \mathrm{g})$, respectively; $\mathrm{k}_{1}$ is the pseudo-first order sorption rate constant $\left(\min ^{1}\right) ; k_{2}$ is the pseudo-second order sorption rate constant (g/mg.min); and $\mathrm{t}$ is the time (min).

In the diffusion model considering an adsorbent with a spherical shape and a relatively short time, the simplified Equation 7 is represented using Equation 6:

$$
q_{t}=K d \cdot t^{0.5}+C
$$

where $\mathrm{Kd}$ is the diffusion intraparticle coefficient ( $\left.\mathrm{mg} / \mathrm{g} \cdot \mathrm{min}^{-0.5}\right)$, and $\mathrm{C}$ is a constant related to diffusion resistance $(\mathrm{mg} / \mathrm{g})$. Kd was determined as a result of linearization of $q_{t}$ as a function of time t. The results for the kinetic parameters are shown in Table 2.

Taking into account the higher values of the correlation

\begin{tabular}{|c|c|c|c|c|c|c|c|}
\hline \multirow{3}{*}{ Kinetics } & \multirow{3}{*}{ Parameters } & \multicolumn{3}{|c|}{ CTGA56 } & \multicolumn{3}{|c|}{ CTGA80 } \\
\hline & & \multicolumn{6}{|c|}{ Concentration $(\mathrm{mg} / \mathrm{L})$} \\
\hline & & 250 & 1250 & 2500 & 250 & 1250 & 2500 \\
\hline \multirow[t]{3}{*}{$1^{\mathrm{a}}$ Order } & $q_{e} 1$ & 78.47 & 48.89 & 253.75 & 61.86 & 36.39 & 31.17 \\
\hline & $\mathbf{k}_{1}$ & 0.002 & 0.017 & 0.039 & 0.016 & 0.018 & 0.013 \\
\hline & $\mathbf{R}^{2}$ & 0.418 & 0.725 & 0.780 & 0.558 & 0.948 & 0.390 \\
\hline \multirow{3}{*}{$2^{\mathrm{a}}$ Order } & $q_{e} 2$ & 0.088 & 909.1 & 2500 & 0.008 & 909.09 & 2000 \\
\hline & $\mathbf{k}_{2}$ & 4.01 & -0.0015 & 0.0003 & -4057.9 & -0.0024 & -0.0025 \\
\hline & $\mathbf{R}^{2}$ & 0.736 & 0.999 & 0.9999 & 0.94 & 1 & 0.9999 \\
\hline \multirow[t]{3}{*}{ Difusion } & C & 87.90 & 985.34 & 2048.1 & 117.93 & 987.24 & 2160.00 \\
\hline & Kd & -3.77 & -2.99 & 18.35 & 0.625 & -3.529 & -1.142 \\
\hline & $\mathbf{R}^{2}$ & 0.173 & 0.578 & 0.939 & 0.006 & 0.863 & 0.076 \\
\hline
\end{tabular}
coefficients $\left(\mathrm{R}^{2}\right)$, it is evident that these data best fit pseudo-second

Table 2. Kinetic parameters for sorption of $\mathrm{Cu}(\mathrm{II})$ on CTGA56 and CTGA80 NPs. 
order kinetics. This model takes into consideration the fact that the adsorption process is limited and controlled by chemical reaction ${ }^{[30]}$, or chemisorption. The adsorption capacity calculated by the model (qe2) is also similar to those determined in the experiments, particularly with increased initial copper concentration $(1250$ and $2500 \mathrm{mg} / \mathrm{L})$. Table 2 also shows that the second order model presented qe 2 theoretical values of 909 and 2500 for CTGA56 and 910 and 2000 for CTGA80. These values are very similar with those provided by the experimental data (961 and 2217 for CTGA56 and 940 and 2170 for CTGA80, from Figure 5). $k 1$ and $k 2$ are related with time scale, where the higher the value, faster the system reaches equilibrium, which may or may not be dependent from the operational conditions ${ }^{[31]}$. In this study, $k 2$, regarding second order kinectis, presented a relative high value only at lower concentration (250ppm). In this case, the low concentration of copper aided to a fast adsorption. The low $\mathrm{R}^{2}$ presented at this particular concentration gives a indications that at lower concentration could be a combined kinetics process.

\subsection{Adsorption Isotherm}

In the next step the experimental data, were fitted by Langmuir and Freundlich isotherm models. This investigation is fundamental in describing the interaction between the solute and the adsorbent, and it represents the surface properties and affinity of the adsorbent at equilibrium. The widely known Langmuir equation, valid for monolayer sorption onto a surface with a finite number of identical sites, can be described in the linear form ${ }^{[32]}$ as in Equation 7:

$$
1 / q_{e}=\left(1 / q_{\operatorname{máx}}\right)+\left(1 / K_{L} q_{\operatorname{máx}} C_{e}\right)
$$

where $\mathrm{q}_{\mathrm{e}}$ and $\mathrm{q}_{\text {mix }}$ are the equilibrium adsorption and maximum adsorption at monolayer coverage $(\mathrm{mg} / \mathrm{g}) ; \mathrm{K}_{\mathrm{L}}$ is a constant related to the affinity of binding sites $(\mathrm{L} / \mathrm{mg}) ; \mathrm{C}_{\mathrm{e}}$ is the final concentration in the solution $(\mathrm{mg} / \mathrm{L})$.

Alternatively, the Freundlich equation also can be used to fit experimental isothermal data to explain adsorption systems, usually in the log-linearized form according to Equation 8:

$$
\log q_{e}=\log K_{F}+(1 / n) \log C_{e}
$$

where $\mathrm{q}_{\mathrm{e}}$ and $\mathrm{q}_{\text {máx }}$ are the equilibrium adsorption and maximum adsorption $(\mathrm{mg} / \mathrm{g}) ; \mathrm{C}_{\mathrm{e}}$ is the final concentration in the solution $(\mathrm{mg} / \mathrm{L}) ; \mathrm{K}_{\mathrm{F}}$ is a Freundlich constant representing the adsorption capacity; and $\mathrm{n}$ is a dimensional constant depicting the adsorption intensity.

The adsorption isotherm parameters were calculated from linear plots of Langmuir and Freundlich isotherm models as $1 / \mathrm{q}_{\mathrm{e}}$ versus $1 / \mathrm{C}_{\mathrm{e}}$ and $\log \mathrm{q}_{\mathrm{e}}$ versus $\log \mathrm{C}_{\mathrm{e}}$, respectively, and the results are shown in Table 3 . The correlation coefficients demonstrate that both models are acceptable, with $\mathrm{R}^{2}>0.9$. However, the Langmuir model presented a higher correlation coefficient of $\mathrm{R}^{2}>0.995$; the parameters also described the experimental data with more accuracy.

Further analysis of the Langmuir equation enables investigation of the dimensionless equilibrium parameter
$R_{L}$ given by Equation 9, where the given value provides an indication of whether or not the adsorption is favorable.

$$
R_{L}=1 /\left(1+K_{L} C_{0}\right)
$$

where $\mathrm{C}_{0}$ is the highest initial solute concentration $(\mathrm{mg} / \mathrm{L})$ and $\mathrm{K}_{\mathrm{L}}$ is the Langmuir constant, which indicates the nature of adsorption.

Briefly, the $R_{L}$ value indicates that the adsorption is favorable if it takes values of $0<R_{L}<1$, and when $R_{L}>1$, adsorption is unfavorable, which means that the metallic ions have more affinity in the liquid phase than in the adsorbent material ${ }^{[33]}$. As shown in Table 3, the $\mathrm{R}_{\mathrm{L}}$ factor for $\mathrm{Cu}(\mathrm{II})$ sorption on the CTGA80 and CTGA56 NPs was 0.24 and 0.31 , respectively. In this case, it is beneficial to consider $\mathrm{Cu}$ (II) monolayer sorption onto surfaces with a finite number of identical sites such as those of CTGA80 and CTGA56 NPs, as the present data suggest that $\mathrm{Cu}(\mathrm{II})$ adsorption on $\mathrm{CTGA}$ NPs is favorable. The sorption capacities were equal to 344.83 and $303.03 \mathrm{mg} / \mathrm{g}$ for CTGA80 and CTGA56 NPs, respectively. These results show that the prepared adsorbent has a very high adsorption capacity compared to previously established values in the literature ${ }^{[24,25,28,29,34-39]}$ as listed in Table 4. Therefore, the present study confirms that NPs CTGA may be an effective adsorbent for the removal of $\mathrm{Cu}(\mathrm{II})$ ions from aqueous solutions.

Table 3. Isotherms parameters for sorption of $\mathrm{Cu}$ (II) on CTGA56 and CTGA80 NPs.

\begin{tabular}{cccc}
\hline Isotherms & Parameters & CTGA56 & CTGA80 \\
\hline Langmuir & $\mathbf{K}_{\mathbf{L}}$ & 0.01275 & 0.00907 \\
& $\mathbf{q}_{\text {máx }}$ & 303.03 & 344.83 \\
& $\mathbf{R}_{\mathbf{L}}$ & 0.24 & 0.31 \\
& $\mathbf{R}^{2}$ & 0.9947 & 0.9999 \\
Freundlich & $\mathbf{K}_{\mathbf{F}}$ & $2.2 \times 10^{-09}$ & $1.9 \times 10^{-07}$ \\
& $\mathbf{n}$ & 0.208 & 0.253 \\
& $\mathbf{R}^{2}$ & 0.9200 & 0.9610 \\
\hline
\end{tabular}

\begin{tabular}{|c|c|c|}
\hline Adsorbent Materials & $\mathbf{q}_{\text {máx }}(\mathrm{mg} / \mathrm{g})-$ & Ref. \\
\hline Chitosan modified by chelating agents & $113.6-55.6$ & [24] \\
\hline $\begin{array}{l}\text { Chitosan chemically modified with the } \\
\text { complexation agent }\end{array}$ & 109.9 & [25] \\
\hline $\begin{array}{l}\text { Thiourea-modified magnetic chitosan } \\
\text { microspheres }\end{array}$ & 66.7 & [28] \\
\hline $\begin{array}{l}\text { Semi-IPN hydrogel based on chitosan } \\
\text { and gelatin }\end{array}$ & 277.04-300.3 & [29] \\
\hline Chitosan with epichlorohydrin & 35.5 & [34] \\
\hline Chitosan-clay nanocomposites & 181.5 & [35] \\
\hline Chitosan-zeolite composites & $14.8-51.3$ & [36] \\
\hline Xanthate-modified magnetic chitosan & 34.5 & [37] \\
\hline Chitosan loaded with Reactive Orange 16 & 107.3 & [38] \\
\hline Recycled chitosan nanofibril & 227.3 & [39] \\
\hline CTGA56 & 303 & This work \\
\hline CTGA80 & 344.8 & This work \\
\hline
\end{tabular}

Table 4. Maximum adsorption capacity of materials based on chitosan for $\mathrm{Cu}(\mathrm{II})$ ions. 


\section{Conclusions}

In summary, core-shell chitosan-arabic gum NPs were produced, characterized, and employed for the adsorption of copper ions in aqueous solution. The results showed that stable particles were produced, with zeta potential values below $-24 \mathrm{mV}$. The stability may be attributed to the carboxylic groups of GA, which successfully coated the CT inner core. Particle size was dependent on the CT content, where the smallest particles were obtained with CTGA56 (250 nm) and the largest were obtained with CTGA80 (660 nm). In the latter case, the excess $\mathrm{CT}$ and their amino groups may have favored intra- and inter-ionic interactions, leading to aggregation of a CT: $\mathrm{P}_{2} \mathrm{O}_{7}^{-4}$ inner core followed by GA coating to form larger particles. The copper adsorption on CTGA56 and CTGA80 NPs was higher than that on pure chitosan. The adsorption of $\mathrm{Cu}$ (II) by CTGA NPs occurred through chemical adsorption that took place on the homogeneous surface of the NPs. In the resulting monolayer adsorption, the functional groups of nitrogen and oxygen atoms likely chelated the $\mathrm{Cu}$ (II) from aqueous solution. With increasing $\mathrm{Cu}(\mathrm{II})$ concentration, CTGA56 provided better performance than CTGA80 because of its smaller particle size, which provides an increased surface area: volume ratio, thereby maximizing the number of active binding sites. Thus, the present study confirms that CTGA NPs may be an effective adsorbent in the treatment of waste water for removal of $\mathrm{Cu}(\mathrm{II})$ ions.

\section{Acknowledgements}

The authors thank Professor Dr. Ana Cristina de Oliveira Monteiro Moreira from Centro de Ciencias da Saúde of Universidade de Fortaleza for use of the spray-dryer, Professor Haroldo César Beserra de Paula from the Laboratório de Biopolímeros of Universidade Federal do Ceará for zeta potential and particle size analysis. This work was supported by the Conselho Nacional de Desenvolvimento Científico - CNPq [Projeto Universal 442965/2014-1]

\section{References}

1. Bhatnagar, A., \& Sillanpää, M. (2009). Applications of chitin- and chitosan-derivatives for the detoxification of water and wastewater-a short review. Advances in Colloid and Interface Science, 152(1-2), 26-38. http://dx.doi.org/10.1016/j. cis.2009.09.003. PMid:19833317.

2. Wu, S. J., Liou, T. H., Yeh, C. H., Mi, F. L., \& Lin, T. K. (2013). Preparation and characterization of porous chitosantripolyphosphate beads for copper(II) ion adsorption. Journal of Applied Polymer Science, 127(6), 4573-4580. http://dx.doi. org/10.1002/app.38073.

3. Islam, M. S., Ahmed, M. K., Raknuzzaman, M., HabibullahAl-Mamun, M., \& Islam, M. K. (2015). Heavy metal pollution in surface water and sediment: a preliminary assessment of an urban river in a developing country. Ecological Indicators, 48, 282-291. http://dx.doi.org/10.1016/j.ecolind.2014.08.016.

4. Dean, J. G., Bosqui, F. L., \& Lanouette, K. H. (1972). Removing heavy metals from waste water. Environmental Science \& Technology, 6(6), 518-522. http://dx.doi.org/10.1021/ es60065a006.
5. Fomina, M., \& Gadd, G. M. (2014). Biosorption: current perspectives on concept, definition and application. Bioresource Technology, 160, 3-14. http://dx.doi.org/10.1016/j. biortech.2013.12.102. PMid:24468322.

6. Crini, G., \& Badot, P.-M. (2008). Application of chitosan, a natural amino polysaccharide, for dye removal from aqueous solutions by adsorption processes using batch studies: a review of recent literature. Progress in Polymer Science, 33(4), 399477. http://dx.doi.org/10.1016/j.progpolymsci.2007.11.001.

7. Modrzejewska, Z., Rogacki, G., Sujka, W., \& Zarzycki, R. (2016). Sorption of copper by chitosan hydrogel: Kinetics and equilibrium. Chemical Engineering and Processing, 109, 104-113. http://dx.doi.org/10.1016/j.cep.2016.08.014.

8. Miretzky, P. J., \& Cirelli, A. F. (2009). Hg(II) removal from water by chitosan and chitosan derivatives: a review. Journal of Hazardous Materials, 167(1-3), 10-23. http://dx.doi. org/10.1016/j.jhazmat.2009.01.060. PMid:19232467.

9. Wan Ngah, W. S., Teong, L. C., \& Hanafiah, M. A. K. M. (2011). Adsorption of dyes and heavy metal ions by chitosan composites: A review. Carbohydrate Polymers, 83(4), 14461456. http://dx.doi.org/10.1016/j.carbpol.2010.11.004.

10. Wu, F. C., Tseng, R. L., \& Juang, R. S. (2010). A review and experimental verification of using chitosan and its derivatives as adsorbents for selected heavy metals. Journal of Environmental Management, 91(4), 798-806. http://dx.doi.org/10.1016/j. jenvman.2009.10.018. PMid:19917518.

11. Lui, B., Wang, D., Yu, G., \& Meng, X. (2013). Adsorption of heavy metal ions, dyes and proteins by chitosan composites and derivatives - A review. Journal of Ocean University of China, 12(3), 500-508. http://dx.doi.org/10.1007/s11802-0132113-0.

12. Li, N., \& Bai, R. (2005). Copper adsorption on chitosan-cellulose hydrogel beads: behaviors and mechanisms. Separation and Purification Technology, 42(3), 237-247. http://dx.doi. org/10.1016/j.seppur.2004.08.002.

13. Ali, B. H., Ziada, A., \& Blunden, G. (2009). Biological effects of gum arabic: a review of some recent research. Food and Chemical Toxicology, 47(1), 1-8. http://dx.doi.org/10.1016/j. fct.2008.07.001. PMid:18672018.

14. Yang, J., Han, S., Zheng, H., Dong, H., \& Liu, J. (2015). Preparation and application of micro/nanoparticles based on natural polysaccharides. Carbohydrate Polymers, 123, 53-66. http://dx.doi.org/10.1016/j.carbpol.2015.01.029. PMid:25843834.

15. Berger, J., Reist, M., Mayer, J. M., Felt, O., \& Gurny, R. (2004). Structure and interactions in chitosan hydrogels formed by complexation or aggregation for biomedical applications. European Journal of Pharmaceutics and Biopharmaceutics, 57(1), 35-52. http://dx.doi.org/10.1016/S0939-6411(03)001607. PMid: 14729079.

16. Lee, J. W., Kim, S. Y., Kim, S. S., Lee, Y. M., Lee, K. H., \& Kim, S. J. (1999). Synthesis and characteristics of interpenetrating polymer network hydrogel composed of chitosan and poly (acrylic acid). Journal of Applied Polymer Science, 73(1), 113-120. http://dx.doi.org/10.1002/(SICI)10974628(19990705)73:1<113::AID-APP13>3.0.CO;2-D.

17. Thinh, N. N., Hanh, P. T. B., Ha, L. T. T., Anh, L. N., Hoang, T. V., Hoang, V. D., Dang, L. H., Khoi, N. V., \& Lam, T. D. (2013). Magnetic chitosan nanoparticles for removal of $\mathrm{Cr}(\mathrm{VI})$ from aqueous solution. Materials Science and Engineering $C$, 33(3), 1214-1218. http://dx.doi.org/10.1016/j.msec.2012.12.013. PMid:23827563.

18. Yu, K., Ho, J., McCandlish, E., Buckley, B., Patel, R., Li, Z., \& Shapley, N. C. (2013). Copper ion adsorption by chitosan nanoparticles and alginate microparticles for water purification applications. Colloids and Surfaces. A, Physicochemical and 
Engineering Aspects, 425, 31-41. http://dx.doi.org/10.1016/j. colsurfa.2012.12.043.

19. Abreu, F. O. M. S., Bianchini, C., Forte, M. M. C., \& Kist, T. B. L. (2008). Influence of the composition and preparation method on the morphology and swelling behavior of alginatechitosan hydrogels. Carbohydrate Polymers, 74(2), 283-289. http://dx.doi.org/10.1016/j.carbpol.2008.02.017.

20. Paula, H. C. B., Sombra, F. M., Cavalcante, R. F., Abreu, F. O. M. S., \& Paula, R. C. M. (2011). Preparation and characterization of chitosan/cashew gum beads loaded with Lippia sidoides essential oil. Materials Science and Engineering C, 31(2), 173-178. http://dx.doi.org/10.1016/j.msec.2010.08.013.

21. Abreu, F. O., Oliveira, E. F., Paula, H. C., \& Paula, R. C. (2012). Chitosan/cashew gum nanogels for essential oil encapsulation. Carbohydrate Polymers, 89(4), 1277-1282. http://dx.doi. org/10.1016/j.carbpol.2012.04.048. PMid:24750942.

22. Zhu, A., Chan-Park, M. B., Dai, S., \& Li, L. (2005). The aggregation behavior of O-carboxymethylchitosan in dilute aqueous solution. Colloids and Surfaces. B, Biointerfaces, 43(34), 143-149. http://dx.doi.org/10.1016/j.colsurfb.2005.04.009. PMid:15941653.

23. Lin, Y. H., Liang, H. F., Chung, C. K., Chen, M. C., \& Sung, W. H. (2005). Physically crosslinked alginate/N,O-carboxymethyl chitosan hydrogels with calcium for oral delivery of protein drugs. Biomaterials, 26(14), 2105-2113. http://dx.doi.org/10.1016/j. biomaterials.2004.06.011. PMid:15576185.

24. Kołodyńska, D. (2012). Adsorption characteristics of chitosan modified by chelating agents of a new generation. Chemical Engineering Journal, 179, 33-43. http://dx.doi.org/10.1016/j. cej.2011.10.028.

25. Justi, K. C., Fávere, V. T., Laranjeira, M. C., Neves, A., \& Peralta, R. A. (2005). Kinetics and equilibrium adsorption of $\mathrm{Cu}(\mathrm{II}), \mathrm{Cd}(\mathrm{II})$, and $\mathrm{Ni}(\mathrm{II})$ ions by chitosan functionalized with 2[-bis-(pyridylmethyl)aminomethyl]-4-methyl-6-formylphenol. Journal of Colloid and Interface Science, 291(2), 369-374. http://dx.doi.org/10.1016/j.jcis.2005.05.017. PMid:15992808.

26. Chang, Y. C., \& Chen, D. H. (2005). Preparation and adsorption properties of monodisperse chitosan-bound $\mathrm{Fe} 3 \mathrm{O} 4$ magnetic nanoparticles for removal of $\mathrm{Cu}(\mathrm{II})$ ions. Journal of Colloid and Interface Science, 283(2), 446-451. http://dx.doi.org/10.1016/j. jcis.2004.09.010. PMid:15721917.

27. Hasan, S., Ghosh, T. K., Viswanath, D. S., \& Boddu, V. M. (2008). Dispersion of chitosan on perlite for enchancement of copper(II) adsorption capacity. Journal of Hazardous Materials, 152(2), 826-837. http://dx.doi.org/10.1016/j. jhazmat.2007.07.078. PMid:17850957.

28. Zhou, L., Wang, Y., Liu, Z., \& Huang, Q. (2009). Characteristics of equilibrium, kinetics studies for adsorption of $\mathrm{Hg}(\mathrm{II})$, $\mathrm{Cu}(\mathrm{II})$, and $\mathrm{Ni}$ (II) ions by thiourea-modified magnetic chitosan microspheres. Journal of Hazardous Materials, 161(2-3), 995-1002. http://dx.doi.org/10.1016/j.jhazmat.2008.04.078. PMid: 18538924.

29. Wang, W. B., Huang, D. J., Kang, Y. R., \& Wang, A. Q. (2013). One-step in situ fabrication of a granular semi-IPN hydrogel based on chitosan and gelatin for fast and efficient adsorption of $\mathrm{Cu}^{2+}$ ion. Colloids and Surfaces. B, Biointerfaces, 106, 51-59. http://dx.doi.org/10.1016/j.colsurfb.2013.01.030. PMid:23434691.

30. Liao, B., Sun, W., Guo, N., Ding, S., \& Su, S. (2016). Equilibriums and kinetics studies for adsorption of $\mathrm{Ni}$ (II) ion onchitosan and its triethylenetetramine derivative. Colloids and Surfaces. A, Physicochemical and Engineering Aspects, 501, 32-41. http:// dx.doi.org/10.1016/j.colsurfa.2016.04.043.

31. Plazinski, W., Rudzinski, W., \& Plazinska, A. (2009). Theoretical models of sorption kinetics including a surface reaction mechanism: A review. Advances in Colloid and Interface Science, 152(1-2), 2-13. http://dx.doi.org/10.1016/j. cis.2009.07.009. PMid:19735907.

32. Itodo, A. U., Itodo, H. U., \& Gafar, M. K. (2010). Estimation of specific surface area using langmuir isotherm method. Journal of Environmental Management, 14(4), 141-146. http://dx.doi. org/10.4314/jasem.v14i4.63287.

33. Dubey, R., Bajpai, J., \& Bajpai, A. K. (2016). Chitosan-alginate nanoparticles (CANPs) as potential nanosorbent for removal of Hg (II) ions. Journal of Environmental Management, 6, 32-44. http://dx.doi.org/10.1016/j.enmm.2016.06.008.

34. Chen, A. H., Liu, S. C., Chen, C. Y., \& Chen, C. Y. (2008). Comparative adsorption of $\mathrm{Cu}(\mathrm{II}), \mathrm{Zn}$ (II), and $\mathrm{Pb}$ (II) ions in aqueous solution on the crosslinked chitosan with epichlorohydrin. Journal of Hazardous Materials, 154(1-3), 184-191. http:// dx.doi.org/10.1016/j.jhazmat.2007.10.009. PMid:18031930.

35. Azzam, E. M., Eshaq, G., Rabie, A. M., Bakr, A. A., Abd-Elaal, A. A., El Metwally, A. E., \& Tawfik, S. M. (2016). Preparation and characterization of chitosan-clay nanocomposites for the removal of $\mathrm{Cu}(\mathrm{II})$ from aqueous solution. International Journal of Biological Macromolecules, 89, 507-517. http:// dx.doi.org/10.1016/j.ijbiomac.2016.05.004. PMid:27151669.

36. Wan Ngah, W. S., Teong, L. C., Toh, R. H., \& Hanafiah, M. A. K. M. (2013). Comparative study on adsorption and desorption of $\mathrm{Cu}(\mathrm{II})$ ions by three types of chitosan-zeolite composites. Chemical Engineering Journal, 223, 231-238. http://dx.doi. org/10.1016/j.cej.2013.02.090.

37. Zhu, Y., Hu, J., \& Wang, J. (2012). Competitive adsorption of $\mathrm{Pb}$ (II), $\mathrm{Cu}$ (II) and $\mathrm{Zn}$ (II) onto xanthate-modified magnetic chitosan. Journal of Hazardous Materials, 221-222, 155-161. http://dx.doi.org/10.1016/j.jhazmat.2012.04.026. PMid:22564487.

38. Vasconcelos, H. L., Guibal, E., Laus, R., Vitali, L., \& Fávere, V. T. (2009). Competitive adsorption of $\mathrm{Cu}$ (II) and $\mathrm{Cd}(\mathrm{II})$ ions on spray-dried chitosan loaded with Reactive Orange 16. Materials Science and Engineering C, 29(2), 613-618. http:// dx.doi.org/10.1016/j.msec.2008.10.022.

39. Liu, D., Li, Z., Zhu, Y., Li, Z., \& Kumar, R. (2014). Recycled chitosan nanofibril as an effective $\mathrm{Cu}(\mathrm{II}), \mathrm{Pb}$ (II) and $\mathrm{Cd}(\mathrm{II})$ ionic chelating agent: adsorption and desorption performance. Carbohydrate Polymers, 111, 469-476. http://dx.doi.org/10.1016/j. carbpol.2014.04.018. PMid:25037377.

Received: Mar. 29, 2017 Revised: Aug. 04, 2017 Accepted: Sept. 04, 2017 